\title{
Inhibition of surface induced coagulation by preadsorption of albumin-heparin conjugates
}

\author{
W. E. Hennink \\ Department of Chemical Technology, Biomaterials Section, Twente University of Technology, \\ Enschede, The Netherlands \\ S. W. Kim \\ Department of Pharmaceutics, University of Utah, Salt Lake City, Utah 84112 \\ J. Feijen \\ Department of Chemical Technology, Biomaterials Section, Twente University of Technology, \\ Enschede, The Netherlands
}

Surface coatings of the albumin-heparin conjugates were developed to improve the blood compatibility of polymeric materials. Glass, PVC, Biomer and cellulose acetate were coated with albumin-heparin conjugate and its adsorption and desorption behavior on glass in particular was studied using ${ }^{3} \mathrm{H}$ and ${ }^{51} \mathrm{Cr}$ radiolabeled conjugates. Precoated materials showed a significant prolongation of the Lee-White clotting time as compared with noncoated ones. It was demonstrated that the prolonged clotting time for pretreated glass was due to surface bound conjugate. Prolonged recalcification times of plasma exposed to glass, Biomer, and PVC were obtained using albumin-heparin conjugate precoated surfaces. Albumin-heparin conjugates with high affinity for antithrombin III gave more prolonged clotting times as low affinity conjugates when used as coatings for glass. This indicates that the behaviour of heparin in preadsorbed conjugates resembles that of heparin in solution.

\section{INTRODUCTION}

In general, a blood compatible material shows low adhesion, aggregation and activation of blood platelets and inhibits the surface induced activation of the intrinsic coagulation. ${ }^{1,2}$ Heparinized polymeric materials, first described by Gott et al., ${ }^{3}$ are generally accepted as being relatively thromboresistant. The preparation and properties of heparinized materials have been reviewed by Leininger, ${ }^{4}$ Ehrlich, ${ }^{5}$ Wilson, ${ }^{6}$ and Ebert and Kim. ${ }^{7}$

The enhanced thromboresistance of materials to which heparin is ionically bound is quite well understood. In contact with blood, a controlled release of heparin from the material surface takes place providing a high concentration of heparin at the blood-polymer interface. ${ }^{8}$ However, the enhanced thromboresistance of some materials to which heparin is covalently bound is not completely understood. It is not clear whether the enhanced thromboresistance is caused by a "solution-like" behavior of heparin or by a specific composition of the protein layer deposited on the heparinized material.

The first explanation is supported by Larsson et al. ${ }^{9}$ and by Goosen et al. ${ }^{10,11}$ who showed that thrombin was neutralized on with heparin modi-

Journal of Biomedical Materials Research, Vol. 18, 911-926 (1984)

(C) 1984 John Wiley \& Sons, Inc.

CCC 0021-9304/84/080911-16\$04.00 
fied polyethylene ${ }^{9}$ and on polyvinyl alcohol gels due to the action of immobilized heparin. ${ }^{10,11}$ Raghunath et al. reported on a covalently bound heparin-collagen complex ${ }^{12}$ and stated that heparin linked to collagen retains its antithrombogenic activity. However, they also showed that a substantial amount of heparin was released in contact with buffer which can very well explain the observed prolonged clotting times. The second explanation is supported by Platé and Valuev ${ }_{r}^{13,14}$ but no information about the preparation of the heparinized materials was provided. Ebert and Kim immobilized heparin onto agarose using alkyl spacer groups of various length. It was shown that the activity of immobilized heparin was dependent on the length of the spacer, whereas the immobilized heparin-platelet interactions were independent on the length of the spacer. ${ }^{15}$

We recently reported on the synthesis and properties of covalently bound conjugates of the plasma protein albumin and the anticoagulant heparin. ${ }^{16}$ These compounds were developed as a coating for mainly hydrophobic blood contacting biomaterials. The adsorption and desorption of albuminheparin conjugates on hydrophobic and hydrophilic polymers were studied and the platelet adhesion from citrated canine blood on biomaterials preadsorbed with albumin-heparin conjugates was investigated using laminar flow cells. ${ }^{17}$ Compared with uncoated materials, the albumin-heparin conjugate preadsorbed materials showed reduced (up to $70 \%$ ) platelet adhesion numbers. Albumin-heparin conjugates were also immobilized onto $\mathrm{CNBr}$ activated Sepharose. Plasma previously exposed to these gels showed a prolonged clotting time which was not due to release of conjugate but was caused by the specific binding of clotting factors IX and XI to the heparin part of the conjugate. ${ }^{18}$ In this study we have investigated the role of heparin in albumin-heparin conjugates preadsorbed onto different surfaces with respect to the inhibition of the surface induced activation of the intrinsic coagulation.

\section{MATERIALS AND METHODS}

\section{Albumin-heparin conjugates}

Albumin-heparin conjugate (further indicated as alb-hep) was obtained by coupling albumin (No. A9511, Sigma, St. Louis) and heparin (porcine mucosa, $170 \mathrm{U} / \mathrm{mg}$, Diosynth, Oss, The Netherlands) at $\mathrm{pH}$ 5.1-5.2 using the coupling agent EDC (1-ethyl-3-(3-dimethylaminopropyl)-carbodiimide). Alb-hep was separated from unreacted albumin and heparin using DEAEcellulose- and Cibacron Blue Sepharose-chromatography, respectively. Albhep was fractionated using affinity chromatograph with an antithrombin II (AT III) Sepharose column yielding high- and low-affinity alb-hep conjugates. ${ }^{16}$ The anticoagulant activity of the different conjugates was determined using an APTT (activated patial thromboplastin time) assay as described previously. ${ }^{18}{ }^{51} \mathrm{Cr}$ radiolabeled alb-hep was prepared as described previously. ${ }^{17} \mathrm{H}$ radiolabeled alb-hep was obtained as follows. Heparin (45 
mg) was radiolabeled with ${ }^{3} \mathrm{H}$ using $\mathrm{NaB}^{3} \mathrm{H}_{4}(1.5 \mathrm{mg}, 6 \mathrm{mCi}$, Amersham, England) according to the method described by Hatton et al. ${ }^{19}$ Subsequently albumin and ${ }^{3} \mathrm{H}$ radiolabeled heparin were coupled using $\mathrm{ECD}$, and ${ }^{3} \mathrm{H}$ radiolabeled alb-hep was isolated using the chromatographic purification procedures described before.

\section{Adsorption and desorption studies}

The adsorption/desorption characteristics of alb-hep $\left({ }^{51} \mathrm{Cr}\right.$ radiolabeled) onto/from cellulose acetate, PVC, Biomer and Silastic were published elsewhere. ${ }^{17}$ The adsorption onto and desorption from glass was studied in two independent experiments using both ${ }^{51} \mathrm{Cr}$ and ${ }^{3} \mathrm{H}$ radiolabeled alb-hep. A solution of ${ }^{51} \mathrm{Cr}$ radiolabeled alb-hep in PBS (1 mL phosphate buffered saline) with the appropriate concentration was pipetted into a glass tube $(7.7 \times 4.6 \mathrm{~mm}$, Payton aggregometer tubes (type 600), Salm and Kipp, Breukelen, The Netherlands) at room temperature. The conjugate solution contacted a glass surface of $6.2 \mathrm{~cm}^{2}$. After the respective adsorption times, the solution of conjugate was removed and the tube was washed five subsequent times with $1.0 \mathrm{~mL}$ aliquots of PBS. The radioactivity on the surface was measured with a gamma counter (LKB, type Wallac 1275, Sweden). For the determination of the rate of adsorption, bulk concentrations of alb-hep of 0.05 and $0.5 \mathrm{mg} / \mathrm{ml}$ were used and the adsorption time was varied ( 30 $\min$ to $5 \mathrm{~h}$ ). The adsorption isotherm of alb-hep on glass was determined by varying the bulk concentration of alb-hep $\left(10^{-3}-10 \mathrm{mg} / \mathrm{ml}\right)$ and applying an adsorption time of one hour. For the determination of the desorption of alb-hep, glass tubes preadsorbed with ${ }^{51} \mathrm{Cr}$ radiolabeled alb-hep $(1 \mathrm{mg} / \mathrm{ml}$, one hour) were contacted with human CPD plasma (Bloodbank Twente and Achterhoek, Enschede, The Netherlands) at room temperature. After removal of the plasma solution followed by a single washing cycle of the surface with PBS, the remaining surface concentration of alb-hep was measured at different time intervals $(15 \mathrm{~min}-5 \mathrm{~h})$. The adsorption of alb-hep conjugate onto glass at room temperature was also studied using ${ }^{3} \mathrm{H}$ labeled conjugate. A solution of ${ }^{3} \mathrm{H}$ labeled alb-hep in PBS $(1 \mathrm{~mL})$ was pipetted into a polystyrene tube $(11.5 \times 55 \mathrm{~mm})$. Then a glass tube (same specifications as used for the experiments with ${ }^{51} \mathrm{Cr}$ labeled conjugate) was brought into this polystyrene tube. Care was taken that the alb-hep solution contacted only the outside of the glass tube (contact area $7.7 \mathrm{~cm}^{2}$ ). After the required adsorption time, the glass tube was removed from the alb-hep solution and the outside of the tube was extensively washed with PBS in order to remove nonadsorbed conjugate. The radioactivity on the surface was measured in the presence of the counting liquid $(4 \mathrm{ml})$ plasmasol (Packard Becker, Brussel, Belgium) using a Packard Tricarb Model 3255 liquid scintillation counter. The observed cpm for all samples were converted into dpm using the SCR (sample channels ratio) and a calibration curve obtained by counting a known amount of ${ }^{3} \mathrm{H}$ in the presence of varying concentrations of acetone. The adsorption of alb-hep on glass was determined by varying the bulk 
concentration of conjugate $\left(10^{-3}-1 \mathrm{mg} / \mathrm{mL}\right)$ and applying an adsorption time of one hour.

\section{Lee-White clotting times}

Glass tubes (Borosilicate $(13 \times 100 \mathrm{~mm})$, Fischer Scientific Company, Pittsburg, Pa.) were coated with Biomer (Ethicon Co., Somersville, N.J.), polyvinyl chloride (PVC, Bentley Laboratories, Irvine, Ca.), or cellulose acetate (CA, acetyl content $39.8 \%$, Aldrich Chemical Co., Milwaukee, Wis.) according to the following procedures. Glass tubes were filled with a $10 \%$ solution of Biomer or PVC in dimethyl acetamide. After emptying the tubes, they were set upright and placed in an oven at $60^{\circ} \mathrm{C}$. After $10 \mathrm{~min}$ and 1 $h$, respectively, any remaining solution was removed from the bottom using a pasteur pipette. After $6 \mathrm{~h}$, the tubes were vacuum dried overnight at the same temperature. Glass tubes were coated with CA using a $5 \%$ solution in acetone. The solvent was removed by slow evaporation for $6 \mathrm{~h}$ at room temperature in an acetone atmosphere.

The uncoated glass tubes and the PVC-, CA- and Biomer ${ }^{\otimes}$-coated tubes were then coated with a solution of alb-hep ${ }^{\circledR}(5 \mathrm{mg} / \mathrm{ml})$ in $0.9 \% \mathrm{NaCl}, 25$ $\mathrm{mM}$ Tris/ $\mathrm{HCl}$, ph 7.4 (buffer A). After an adsorption time of $1 \mathrm{~h}$, the tubes were thoroughly washed with buffer $\mathrm{A}$ in order to remove nonadsorbed alb-hep. After the last washing cycle, $1 \mathrm{~mL}$ of blood was added to both the uncoated glass, the PVC-, CA-, and Biomer-coated tubes (controls) and the tubes coated with alb-hep. The control tubes were incubated with buffer A for one hour before the addition of the blood. Using a double syringe technique, blood samples were drawn from anesthetized dogs via Angiochat Teflon catheter (The Deseret Co., Sandy, U.S.A.) which was inserted into the jugular vein. Lee-White clotting times were determined as described by Coleman et al. ${ }^{20}$

The effect of preadsorbed albumin or different alb-hep conjugates on the Lee-White clotting times was investigated using glass as a substrate. Glass tubes were preadsorbed for $1 \mathrm{~h}$ with solutions $(5 \mathrm{mg} / \mathrm{mL}$ in buffer A) of either albumin, alb-hep, high affinity alb-hep or low affinity alb-hep. After washing the tubes with buffer $\mathrm{A}$, Lee-White clotting times were determined. In addition, the relationship between the alb-hep blood concentration and the Lee-White clotting time was established by measuring clotting times of $1 \mathrm{~mL}$ amounts of blood which were added to glass tubes (uncoated) containing different amounts of alb-hep in buffer A $(2,4,6,8, \mu \mathrm{L}$ of a solution of $1 \mathrm{mg} / \mathrm{mL}$ ). All Lee-White determinations were carried out at $37^{\circ} \mathrm{C}$.

\section{Plasma recalcification times}

The recalcification times of plasma in contact with uncoated and with albhep coated glass, PVC and Biomer were determined. The clotting time of plasma after the addition of calcium chloride was measured by continuously following the turbidity of plasma using a two-channel Payton aggregometer 


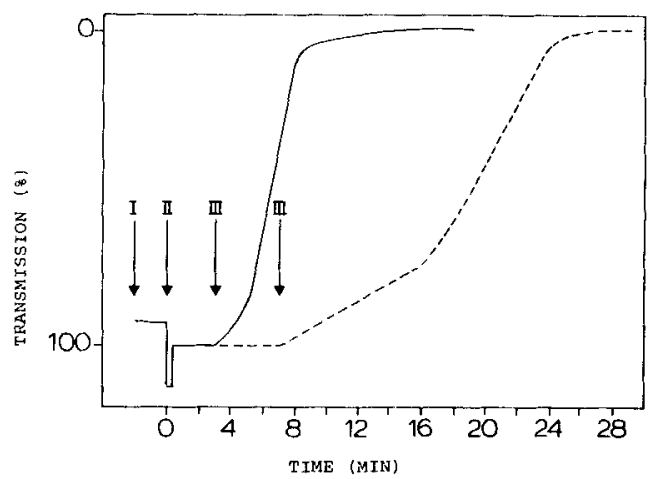

Figure 1. Change in transmission (\%) as a function of time of recalcified citrated plasma exposed to uncoated glass $(-)$ and to glass previously coated with albumin-heparin conjugate $(10 \mu / \mathrm{mL}, 1 \mathrm{~h})(---)$. Arrows indicate: $\mathrm{I}$, incubation for $2 \mathrm{~min}$ at $37^{\circ} \mathrm{C}$ of citrated plasma in a glass tube; II, addition of $\mathrm{CaCl}_{2} ; \mathrm{III}$, stage where the first fibrin polymers are formed and taken as "the recalcification time."

(Salm and Kipp, Breukelen, The Netherlands). All measurements were carried out with glass tubes $(7.7 \times 46 \mathrm{~mm}$, Payton aggregometer tubes (type $600)$, Salm and Kipp, Breukelen, The Netherlands) and with glass tubes coated with PVC and Biomer. The same coating procedure for glass with PVC and Biomer was followed as described under the "Lee-White clotting times" section. Plasma recalcification times were measured according to the following procedure. Human CPD plasma ( $350 \mu \mathrm{l}$, Bloodbank Twente and Achterhoek, Enschede, The Netherlands) was pipetted into a tube. This tube was placed into the aggregometer thermostated at $37^{\circ} \mathrm{C}$. After an incubation time of exactly $2 \mathrm{~min}, \mathrm{CaCl}_{2}(50 \mu \mathrm{L}, 100 \mathrm{mM}$ in buffer A) was added and the turbidity of the plasma solution was measured against a reference. This reference was a fully coagulated sample of plasma obtained by mixing plasma $(350 \mu \mathrm{L})$ and $\mathrm{CaCl}_{2}(50 \mu \mathrm{L}, 100 \mathrm{mM}$ in buffer $\mathrm{A})$ followed by an incubation period of $30 \mathrm{~min}$. Examples are given for glass and glass pretreated with alb-hep (Fig. 1). The time where the transmission is decreasing (arrow III in Fig. 1) is taken as the plasma recalcification time.

PVC and Biomer were coated with a solution of alb-hep $(0.1 \mathrm{mg} / \mathrm{mL}$ in buffer A) for $1 \mathrm{~h}$. After removing the nonadsorbed conjugate by washing the tubes thoroughly with buffer A, plasma was added and the recalcification time was determined as described above. Control experiments were carried out by measuring recalcification times of plasma in contact with nontreated and with albumin coated $(0.1 \mathrm{mg} / \mathrm{mL}$ in buffer $A$ for one hour) PVC and Biomer. The effect on the recalcification time of plasma in contact with glass previously pretreated with varying concentrations of respectively albumin, alb-hep, high affinity alb-hep and low affinity alb-hep in buffer A was also studied. Adsorption times of one hour were applied and the tubes were washed thoroughly with buffer A before the addition of the plasma.

In order to establish the relationship between the alb-hep concentration in plasma and the plasma recalcification time, small volumes of alb-hep (0.5- 


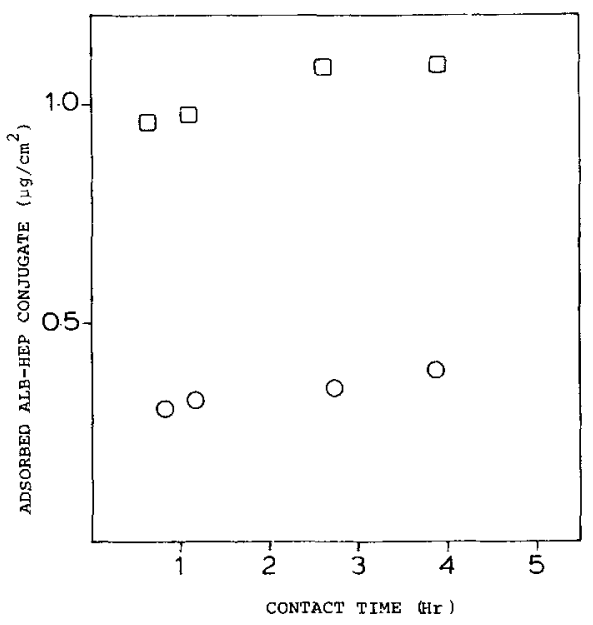

Figure 2. The adsorption of alb-hep conjugate onto glass as a function of time. (O) $0.05 \mathrm{mg} / \mathrm{mL} ;(\square) 0.5 \mathrm{mg} / \mathrm{mL}$. Measurements were carried out using ${ }^{51} \mathrm{Cr}$ radiolabeled albumin-heparin conjugate.

$8 \mu \mathrm{L}$ of a $1 \mathrm{mg} / \mathrm{mL}$ solution in buffer $\mathrm{A}$ ) were mixed with $350 \mu \mathrm{L}$ of plasma and the recalcification times were measured as described below. These measurements were carried out for plasma in contact with glass, PVC or Biomer.

To determine the effect of desorbed conjugate on the plasma recalcification times, an additional experiment was carried out. Twelve glass tubes were incubated with a $10 \mu \mathrm{g} / \mathrm{mL}$ solution of alb-hep. After an incubation time of $2 \mathrm{~min}$ at $37^{\circ} \mathrm{C}$, recalcification times of plasma of six tubes were measured. After $15 \mathrm{~min}$ of incubation at $37^{\circ} \mathrm{C}$, the plasma of the other 6 tubes was transferred to 6 uncoated glass tubes and recalcification times were measured.

Special attention was given in handling the plasma for the recalcification experiments. The plasma was received deep frozen $-70^{\circ} \mathrm{C}$ in $200 \mathrm{~mL}$ batches. It was thawed quickly at $37^{\circ} \mathrm{C}$, divided into $10 \mathrm{~mL}$ portions and stored at $-30^{\circ} \mathrm{C}$ in polypropylene vials. Before each experiment the plasma was thawed at $37^{\circ} \mathrm{C}$ and stored in an ice bath. Plasma was not used for a longer period than $3 \mathrm{~h}$ after being thawed.

\section{RESULTS}

\section{Adsorption-desorption behavior of alb-hep at glass surfaces}

Figures 2, 3, and 4 show the adsorption and desorption characteristics of alb-hep on glass using both ${ }^{3} \mathrm{H}$ and ${ }^{51} \mathrm{Cr}$ labeled conjugate. From Figure 2 it appears that the plateau value for adsorption is reached within $1 \mathrm{~h}$. Figure 3 shows the adsorption isotherm of alb-hep on glass. Within the range where experiments were carried out using ${ }^{3} \mathrm{H}$ and ${ }^{51} \mathrm{Cr}$ labeled alb-hep $(0.001-1 \mathrm{mg} / \mathrm{mL})$, results obtained with both labels are in good agreement. Due to the elaborate synthetic procedures involved, the adsorption with ${ }^{3} \mathrm{H}$ 


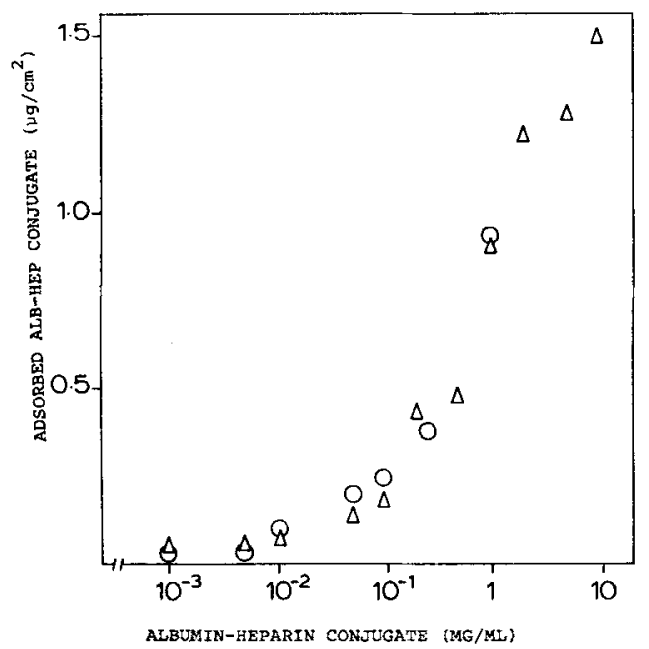

Figure 3. Adsorption of albumin-heparin conjugate on glass using ${ }^{51} \mathrm{Cr}(\triangle)$ and ${ }^{3} \mathrm{H}(\mathrm{O})$ radiolabeled conjugate.

labeled conjugate was only studied at bulk concentrations up to $1 \mathrm{mg} / \mathrm{ml}$. Figure 4 shows the desorption of alb-hep from glass in the presence of plasma. During the first $30-60 \mathrm{~min}$ of contact with plasma, $50-60 \%$ of the adsorbed conjugate is exchanged by plasma proteins and thereafter no further desorption is observed.

\section{Lee-White clotting times}

Lee-White clotting times of whole blood in contact with glass, CA, Biomer, and PVC with and without an alb-hep coating were determined. As a reference, the clotting time of blood in contact with glass was measured for each experiment. This value varied from 8-12 min. The observed clotting times for blood in contact with the different materials were divided by the

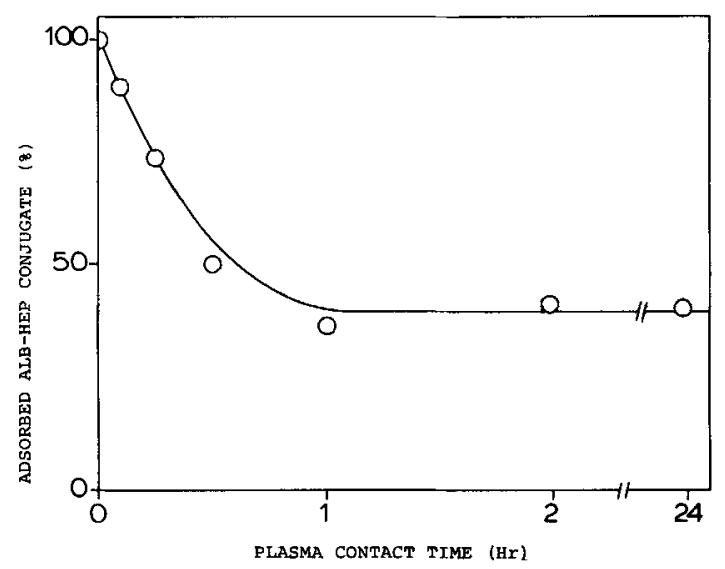

Figure 4. Desorption of albumin-heparin conjugate from glass in the presence of citrated plasma as a function of time. 


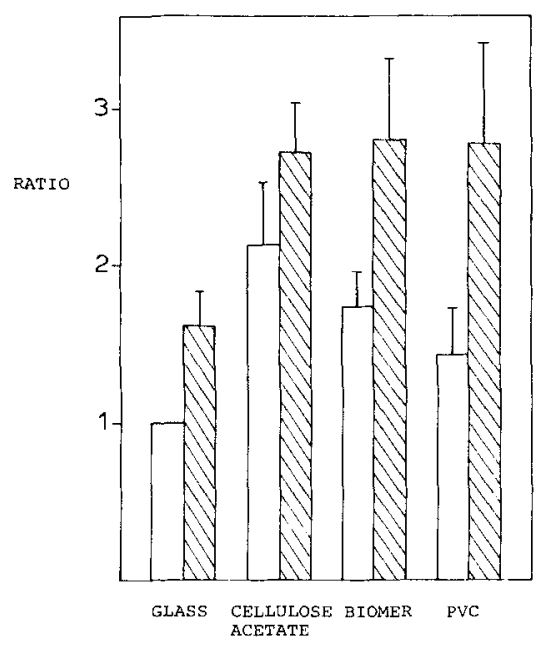

Figure 5. Ratios of Lee-White clotting times of blood exposed to different materials both uncoated $(\square)$ and coated with albumin-heparin conjugate (5 $\mathrm{mg} / \mathrm{ml})([)$ All plotted values are the means ( \pm S.D.) of eight experiments.

value observed for glass yielding clotting time ratios given in Figure 5. Average ratios were obtained by repeating the experiments several times $(N=$ 8) using five different dogs. From Figure 5 it appears that the Lee-White clotting time is prolonged when the different materials were preadsorbed with alb-hep. This prolongation is dependent on the type of material tested and varied from $30 \%$ (CA) to $100 \%$ (PVC).

Figure 6 shows the Lee-White clotting times of blood in contact with glass which was previously treated with albumin or with different alb-hep conjugates. From this figure it appears that, compared with uncoated glass, an albumin coating hardly affected the Lee-White clotting time. On the other hand glass preadsorbed with different alb-hep conjugates show strong

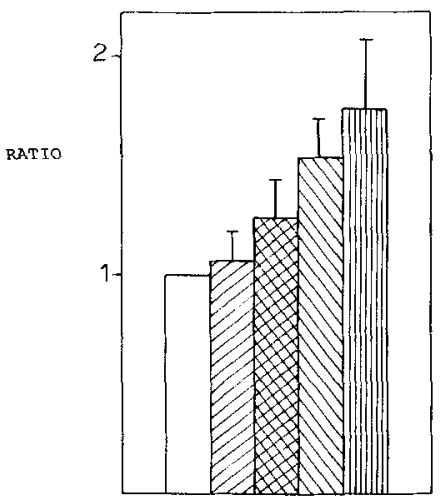

Figure 6. Ratios of Lee-White clotting times of blood exposed to glass coated with albumin $(\square)$, glass coated with low-affinity albumin-heparin conjugate $(\square)$, glass coated with nonfractionated albumin-heparin conjugate ( $\$$ ), glass coated with high-affinity albumin-heparin conjugate ( $\mathbb{(})$, and uncoated glass

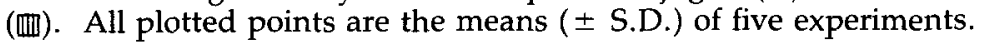


TABLE I

Statistical Significance of Differences in Lee-White Clotting Times of Blood Exposed to Glass Pretreated with Albumin and Different Albumin-Heparin Conjugates as shown in Figure 6 using Student's $t$-test

\begin{tabular}{lcccc}
\hline \multicolumn{1}{c}{ Type of coating } & $\begin{array}{c}\text { Nonfractionated } \\
\text { alb-hep } \\
\text { conjugate }\end{array}$ & $\begin{array}{c}\text { Low-affinity } \\
\text { alb-hep } \\
\text { conjugate }\end{array}$ & Albumin & $\begin{array}{c}\text { Uncoated } \\
\text { glass }\end{array}$ \\
\hline $\begin{array}{l}\text { High-affinity alb-hep } \\
\text { Nonfractionated }\end{array}$ & $0.01<p<0.02$ & $0.01<p<0.02$ & $<0.01$ & $<0.01$ \\
$\quad$ alb-hep & & $0.05<p<0.1$ & $<0.01$ & $<0.01$ \\
$\begin{array}{l}\text { Low-affinity alb-hep } \\
\text { Albumin }\end{array}$ & & & $<0.01$ & $<0.01$ \\
\hline
\end{tabular}

differences. The strongest prolongation is observed for glass preadsorbed with high affinity alb-hep, whereas for low affinity alb-hep only a slight prolongation is observed. Table I gives a statistical analysis of the results of Figure 6. From this table it appears that, except for the combinations nonfractionated alb-hep conjugate-low-affinity conjugate and albumin-uncoated, all mean values differ significantly ( $p<0.05$, Student's $t$-test).

Figure 7 gives the relationship between the concentration of alb-hep in blood and the Lee-White clotting times of these blood samples exposed to uncoated glass.

\section{Plasma recalcification times}

A typical plot of the turbidity (\% transmission) of plasma in contact with glass (untreated and treated with alb-hep) is shown in Figure 1. After the addition of $\mathrm{CaCl}_{2}(t=0)$ no decrease in $\%$ transmission is observed during $3 \mathrm{~min}$ for uncoated glass and during $7 \mathrm{~min}$ for glass previously treated with alb-hep $(10 \mu \mathrm{g} / \mathrm{mL}$ in buffer $\mathrm{A})$. After that the transmission is decreasing which is caused by polymerization and cross-linking of formed fibrin monomers.

The results of plasma recalcification time studies are presented in the

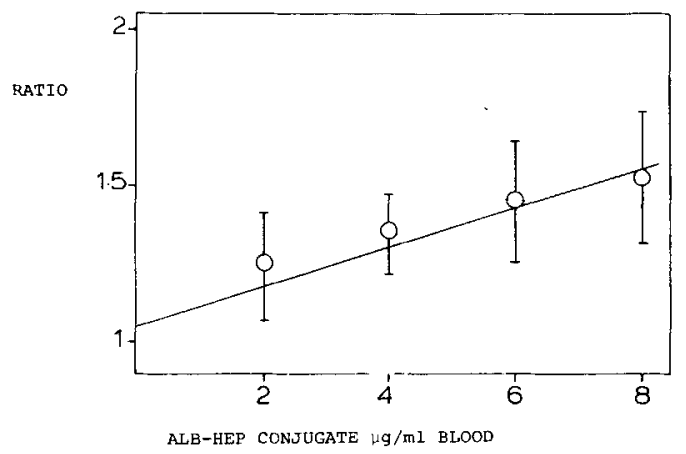

Figure 7. Ratios of Lee-White clotting times of blood in the presence of different concentrations of albumin-heparin conjugate and blood in the absence of albumin-heparin conjugate. All plotted points are the means ( \pm S.D.) of five experiments. 


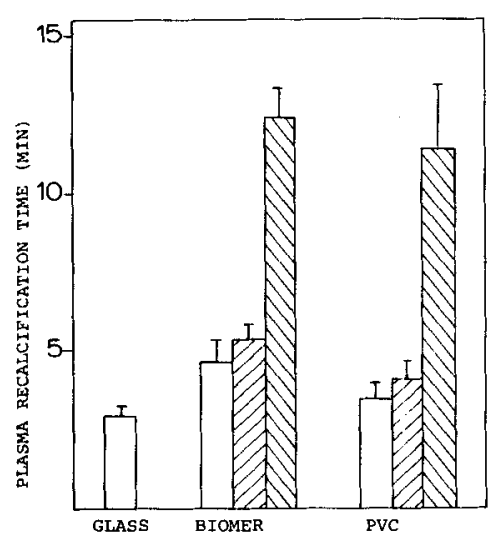

Figure 8. Recalcification times of plasma exposed to uncoated ( $\square$ ) with al-

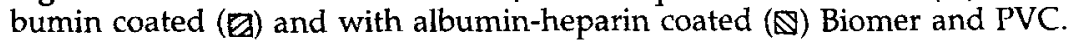

Figures 8 through 12 . Figure 8 shows that the recalcification times of plasma exposed to Biomer and PVC precoated with alb-hep conjugate are strongly prolonged (170 and $220 \%$ as compared with uncoated Biomer and PVC, respectively), whereas as a precoating with albumin gives only a slight prolongation (15 and $14 \%$ ). When glass is contacted with solutions containing varying concentrations of alb-hep, a curve as shown in Figure 9 is observed. A prolongation of the plasma recalcification time of almost $400 \%$ is obtained when glass was precoated with a $0.03 \mathrm{mg} / \mathrm{mL}$ solution of alb-hep. When higher concentrations for the coating were used (up to $10 \mathrm{mg} / \mathrm{mL}$ ), no further prolongation was observed. It was found that the concentration of the albhep solution used for coating of the glass tubes which induced a plateau value in the plasma recalcification time as well as the slope of the linear part of the plot, were both dependent on the batch of plasma used. Figure 10 shows the plasma recalcification time as a function of the albumin concentration used for coating of the glass tubes. It appears that in the concentration range $(0-0.03 \mathrm{mg} / \mathrm{mL})$ where alb-hep conjugate affects the clotting to a high extent, an albumin coating does not cause a significant prolongation of the plasma recalcification time. As expected, heparin does not absorb onto glass. Glass tubes were contacted with a solution of heparin $(1 \mathrm{mg} /$ $\mathrm{mL}$ ) for $1 \mathrm{~h}$. After washing, plasma was added and the recalcification time was measured. The observed average recalcification time was the same as for plasma exposed to uncoated glass. Figure 11 shows the recalcification times of plasma in contact with glass which was previously treated with different alb-hep conjugates. From this figure it can be observed that a coating of high affinity alb-hep conjugate is 2-4 times more effective in preventing surface induced coagulation than a corresponding coating of nonfractionated conjugate, whereas a coating of low-affinity conjugate does not have any effect on the plasma recalcification time in the concentration range shown.

Relationships between plasma alb-hep concentration and recalcification times of this plasma exposed to glass, Biomer and PVC were established. Figure 12 gives the results. 


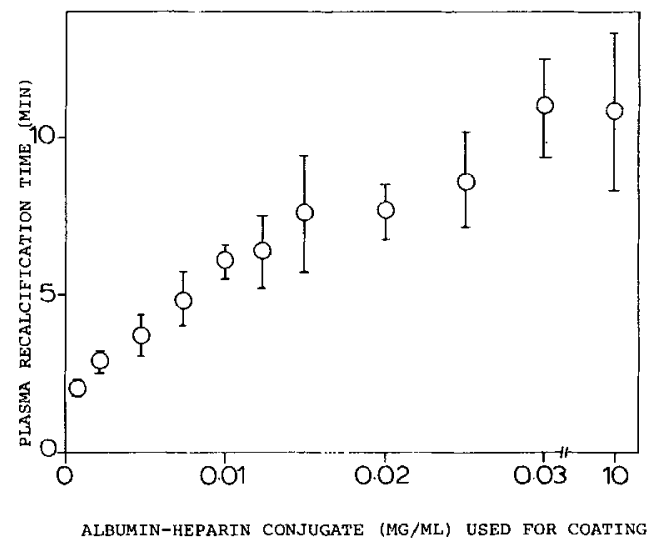

Figure 9. Recalcification times of plasma exposed to glass previously treated with buffer solutions containing different concentrations of albumin-heparin conjugate.

Table II shows the results of the recalcification times of plasma exposed to glass pretreated with alb-hep, the recalcification times of plasma exposed to the same tubes and transferred to uncoated tubes after an incubation time of $15 \mathrm{~min}$ and the recalcification time of plasma exposed to uncoated glass.

\section{DISCUSSION}

The adsorption and desorption characteristics of alb-hep conjugate on glass are to some extent comparable with data measured for the adsorption onto and desorption from the hydrophobic polymers Biomer, PVC, and Silastic. ${ }^{17}$ Plateau values are reached within one hour for the adsorption of alb-hep onto both glass and the polymers mentioned above. In contact with plasma, exchange of adsorbed alb-hep with plasma proteins is observed for both glass and the hydrophobic polymers and there is also agreement with respect to the amount of adsorbed conjugate which is released into the

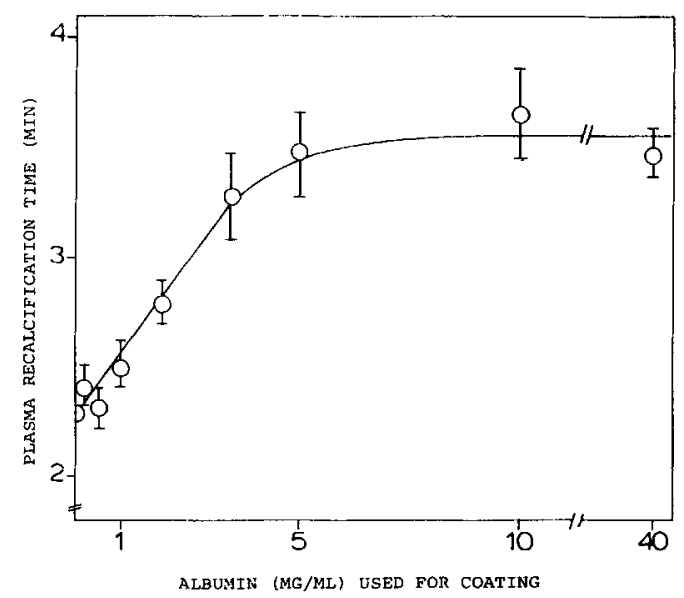

Figure 10. Recalcification times of plasma exposed to glass previously treated with buffer solutions containing different concentrations of albumin. 


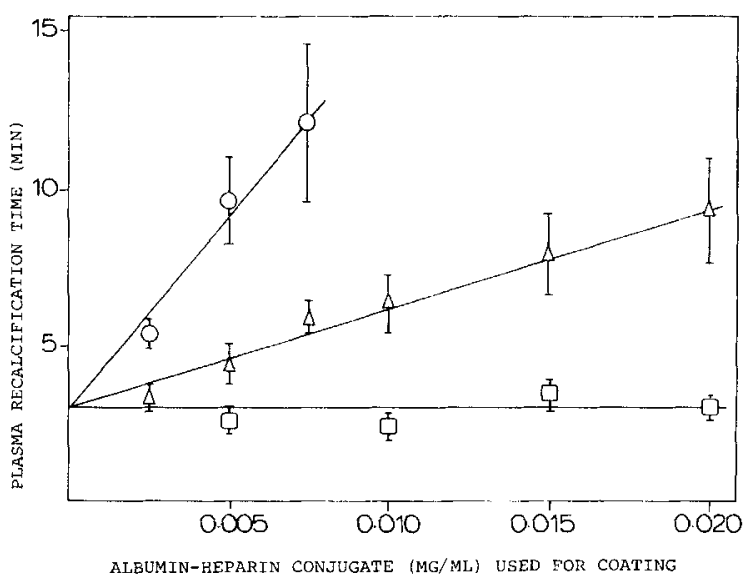

Figure 11. Recalcification times of plasma exposed to glass previously treated with buffer solutions containing different concentrations of nonfractionated albumin-heparin conjugate $(\triangle)$, low-affinity albumin-heparin conjugate $(\square)$, and high-affinity albumin-heparin conjugate $(O)$.

plasma. For glass, Biomer, PVC, and Silastic within the first $1-2 \mathrm{~h}$ of contact between the materials preadsorbed with alb-hep and plasma, approximately $50 \%$ of the adsorbed amount of conjugate is exchanged and after that no further release is observed. Similar desorption curves have been published by Baszkin and Lyman for prealbuminated polymers in contact with plasma. ${ }^{21}$ The adsorption isotherm of alb-hep on glass (Fig. 3) deviates from the ones published for Biomer, PVC, and Silastic. ${ }^{17}$ For the latter polymers, surface concentrations of $0.5-0.6 \mu \mathrm{g} / \mathrm{cm}^{2}$ at a bulk concentration of $10 \mathrm{mg} /$ ml were observed, whereas for glass, at the same bulk concentration a value of $1.5 \mu \mathrm{g} / \mathrm{cm}^{2}$ was measured. The results obtained with ${ }^{3} \mathrm{H}$ labeled alb-hep and ${ }^{51} \mathrm{Cr}$ labeled are in agreement with each other which suggests that (on glass) no preferential adsorption of labeled conjugate occurs.

The results obtained with the Lee-White tests demonstrate that, compared

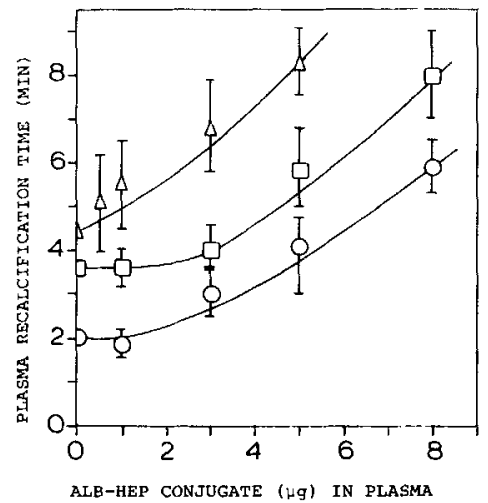

Figure 12. Recalcification times of plasma $(350 \mu \mathrm{L})$ containing different amounts of albumin-heparin conjugate, exposed to glass $(O)$, Biomer $(\triangle)$, and PVC (ㅁ). 
TABLE II

Recalcification Times of Plasmas (in minutes \pm S.D., $N=6$

\begin{tabular}{ccc}
\hline $\begin{array}{c}\text { Exposed to glass } \\
\text { pretreated with } \\
\text { alb-hep }\end{array}$ & $\begin{array}{c}\text { Exposed to glass pretreated } \\
\text { with alb-hep and transferred } \\
\text { to uncoated glass tubes }\end{array}$ & $\begin{array}{c}\text { Exposed to uncoated } \\
\text { glass tubes }\end{array}$ \\
\hline $6.6 \pm 1.0$ & $2.8 \pm 0.2$ & $3.0 \pm 0.3$ \\
\hline
\end{tabular}

with uncoated materials, the clotting times of whole blood exposed to materials (glass, Biomer, PVC, CA) previously treated with alb-hep are significantly prolonged. Using the data presented in Figures 3 and 4, it can be calculated that the maximum amount of conjugate released into the blood $(1 \mathrm{~mL})$ within 20 min of contact (maximum clotting time observed for glass preadsorbed with alb-hep) is $1 \mu \mathrm{g}$, assuming that the desorption behaviour of alb-hep in the presence of whole blood is the same as in the presence of citrated plasma. From Figure 7 it appears that this amount of released albhep causes only a slight prolongation (10-20\%) of the Lee-White clotting time. So it can be concluded that the observed prolongation of the LeeWhite clotting time can not be described to the release of adsorbed alb-hep into the blood phase. Figure 6 shows that preadsorption of glass with albumin gives a minor prolongation of Lee-White clotting times. Therefore we expect that albumin in alb-hep also will not contribute to the observed prolongation in Lee-White clotting times.

This means that the effects are due to surface adsorbed alb-hep conjugate. The observed clotting time of whole blood exposed to a material is the result of both activation of the intrinsic coagulation as well as platelet adsorption and activation on this material surface. Therefore, using only the results of the Lee-White tests, it is difficult to evaluate the mechanism of the surface bound alb-hep induced inhibition of the coagulation. Figure 6 shows that surface bound high affinity alb-hep is a better inhibitor of the surface induced coagulation than low-affinity alb-hep. From this we conclude, assuming that the rate of activation of the intrinsic coagulation is the same on both surfaces, that the heparin part of the surface bound alb-hep neutralizes activated clotting factors formed at the material-blood interface. Since we observed that the initial platelet adhesion onto materials preadsorbed with alb-hep was strongly reduced and that a material preadsorbed with different conjugates (low- and high-affinity) showed different platelet adhesion numbers, ${ }^{17}$ it can not be excluded that the prolonged Lee-White clotting times are also due to reduced platelet adhesion and activation on the material surface.

The results obtained from the recalcification time studies clearly show that the recalcification times of plasma in contact with Biomer, PVC, and glass preadsorbed with alb-hep were strongly prolonged. Using the adsorption and desorption data of alb-hep available for glass (Figure 3 and 4) and for Biomer and $\mathrm{PVC}^{17}$ and a contact area between the surface and the plasma of $2.5 \mathrm{~cm}^{2}$, it can be calculated that the maximum amounts of alb-hep which 
are released into the plasma during the recalcification measurements are $0.06,0.03$, and $0.04 \mu \mathrm{g}$ for glass, Biomer, and PVC, respectively. From this it can be concluded, using the data of Figure 12, that the observed prolongations of the recalcification times of plasma exposed to glass, Biomer, and PVC previously coated with alb-hep cannot be ascribed to release of conjugate from the surface. This conclusion is confirmed by the results presented in Table II. Since the observed prolonged plasma recalcification times can not be ascribed to the release of conjugate into the plasma nor to the albumin part of adsorbed conjugate (Figure 10), we conclude that surface bound alb-hep is a very effective inhibitor of the surface induced activation of the intrinsic coagulation. Using different conjugates (nonfractionated, high- and low-affinity, Figure 11) more information is obtained about the mechanism of surface bound alb-hep conjugate inhibition of the activation of the intrinsic coagulation. Preadsorption of glass with low affinity conjugate does not influence the recalcification time of plasma, whereas preadsorption with high affinity conjugate strongly prolonged the plasma recalcification time. Surface bound nonfractionated alb-hep has an activity which is $30-50 \%$ of the activity of high affinity conjugate. These results show a strong resemblance with literature data available for the solution behaviour of heparin fractionated with immobilized AT III. 22,23 Therefore we conclude that the mechanism of action of surface bound alb-hep is the same as proposed for bulk heparin. ${ }^{24}$ The observation that after exposure to plasma a substantial amount of AT III was detected on polystyrene treated with albhep, ${ }^{25}$ supports the proposed mechanism. This mechanism is different from that proposed by Goosen et al., ${ }^{10,11}$ who stated that AT III reacts after that thrombin is bound to covalently bound heparin. However, Goosen et al. only consider the inactivation of thrombin and they do not pay attention to the fact that heparin and AT III were also able to neutralize the activity of other activated clotting factors (Xa, IXa, XIa and XIIa). ${ }^{26-29}$ In addition, thrombin is very active in the blood coagulation (e.g., stimulation of platelet aggregation, stimulation of its own formation) and therefore it is likely that when (traces of) thrombin are formed, thrombus formation can hardly be avoided. This means that a heparinized material, when effective in the inhibition of fibrin formation, probably inhibits the generation of thrombin rather than thrombin activity, which was demonstrated with soluble heparin. ${ }^{30}$

In conclusion, surface bound alb-hep is very effective in inhibiting the surface induced coagulation, as measured with Lee-White clotting times and plasma recalcification times. It was demonstrated that release of adsorbed conjugate from the surface into the plasma (blood) does not cause the observed prolongation of clotting times. It was shown that AT III interacting with alb-hep conjugate is involved in the inhibition of the intrinsic coagulation at the plasma material interface. From this, we conclude that the mechanism of action of heparin present in the surface bound alb-hep conjugate is similar to that of bulk heparin.

The authors thank Dr. D. L. Coleman for valuable discussions and teaching one of us 
(W. H.) the Lee-White clotting technique. We are indebted to Mr. T. Dijkstra and Ir. J. P. Detmers (hospital 'Ziekenzorg') for preparing the radiolabeled conjugates and providing facilities for working with these compounds. This research was supported by NIH Grant HL-17623-09.

\section{References}

1. J. Feijen, T. Beugeling, A. Bantjes, and C. T. Smit Sibinga, "Biomaterials and Interfacial Phenoma," in Advances in Cardiovascular Physics 3, D. N. Ghista, Ed., Karger Basel, 1979, pp. 100-132.

2. J. Feijen, "Thrombogenesis Caused by Blood-Foreign Surface Interaction," in Artificial Organs. Proceedings of a Seminar on the Clinical Application of Membrane Oxygenators and Sorbent Based Systems, R. M. Kenedi, J. M. Courtney, J. D. S. Gaylor, T. Gilchrist, Eds. MacMillan, New York, 1975, pp. 235-247.

3. V. L. Gott, J. D. Whiffen, and R. C. Datton, "Heparin Bonding on Colloidal Graphite Surfaces," Science, 142, 1297 (1963).

4. R. I. Leininger, "Polymeric Materials that Don't Clot Blood," Chem. Techn., 5, 172-176 (1975).

5. J. Ehrlich, "Long Term Thromboresistance of Heparinized Materials," Polymer Engineering and Science, 15, 281-285 (1975).

6. J. E. Wilson, "Heparinized Polymers as Thromboresistant Biomaterials," Polym. Plast. Technol. Eng., 16, 119-220 (1981).

7. C. D. Ebert and S. W. Kim, "Heparin/Polymers for the Prevention of Surface Thrombosis," Chapter in Medical Application of Controlled Release Technology, Robert Langer, Ed. CRC Press, Baca Raton, in press.

8. Y. Idezuki, H. Watanabe, M. Hagiwara, K. Kanasygi, Y. Mori, S. Nagaoka, M. Hagio, K. Yamamoto, and H. Tanzawa, "Mechanism of Antithrombogenicity of a new Heparinized Polymer: Chronic in Vivo Studies and Clinical Application," Trans. Am. Soc. Artif. Intern. Organs, 21, 436-438 (1975).

9. R. Larsson, P. Olsson, and U. Lindahl, "Inhibition of Thrombin on Surfaces Coated with Immobilized Heparin and Heparin-like Polysaccharides: A Crucial Non-Thrombogenic Principle," Thromb. Res., 19, 43-55 (1980).

10. M. F. A. Goosen, M. W. Selfton, and H. W. C. Hatton, "Inactivation of Thrombin by Antithrombin III on a Heparinized Biomaterial," Thromb. Res., 20, 543-554 (1980).

11. M. F. A. Goosen and M. V. Sefton, "Properties of a Heparin-Poly (vinyl alcohol) Hydrogel Coating," J. Biomed. Mater. Res., 17, 359-373 (1983).

12. K. Ragnuath, G. Biswas, K. Pandurange Rao, K. T. Joseph, and M. Chvapil, "Some Characteristics of Collagen-Heparin Complex," J. Biomed. Mater. Res., 17, 613-621 (1983).

13. N. A. Platé and L. I. Valuev, "On the Mechanism of Enhanced Thromboresistance of Polymeric Materials in the Presence of Heparin," Biomaterials, 4, 14-20 (1983).

14. N. A. Platé and L. I. Valuev, "On the Interaction of Heparin-Containing Polymers with Plasma Proteins and Blood," Thromb. Res., 27, 131-140 (1982).

15. C. D. Ebert and S. W. Kim, "Immobilized Heparin: Spacer Arm Effects on Biological Interactions," Thromb. Res., 26, 43-57 (1982).

16. W. E. Hennink, J. Feijen, C. D. Ebert, and S. W. Kim, "Covalently Bound Conjugates of Albumin and Heparin: Synthesis, Fractionation and Characterization," Thromb. Res., 29, 1-13 (1983).

17. W. E. Hennink, L. Dost, J. Feijen, and S. W. Kim, "Interaction of Albumin-Heparin Conjugate Preadsorbed Surfaces with Blood," Trans. Am. Soc. Artif. Organs, 29, 200-205 (1983).

18. W. E. Hennink, L. Dost, S. W. Kim, W. G. van Aken, and J. Feijen, 
"Blood Compatibility of Albumin-Heparin Conjugate Treated Surfaces," Proceedings of Biomaterials in Artificial Organs, the fifth Seminar in the Series of Strathclyde Bioengineering Seminars, University of Strathclyde, Glasgow, U.K., 12-13 Sept., in press.

19. H. W. C. Hatton, L. R. Berry, H. Kaur, A. Koj, and E. Regoeczi, "Chromatography of Heparin on Sepharose-Lysine: Molecular Size Fractionation and its Relevance to Thrombin and Antithrombin III Binding," Canadian Journal of Biochemistry, 57, 1183-1190 (1973).

20. D. L. Coleman, D. E. Gregonis, and J. D. Andrade, "Blood-Materials Interaction: the Minimum Interfacial Free Energy and the Optimum Polar/Apolar Ratio Hypotheses," J. Biomed. Mater. Res., 16, 381-398 (1982).

21. A. Baszkin and J. Lyman, "The Interaction of Plasma Proteins with Polymers. I. Relationship between Polymer Surface Energy and Protein Adsorption/Desorption," J. Biomed. Mater. Res, , 14, 393-403 (1980).

22. M. Hook, I. Björk, J. Hopwood, and U. Lindahl, "Separation of Highand Low-Activity Heparin Species by Affinity Chromatography on Immobilized Antithrombin III," FEBS Lett., 66, 90-93 (1976).

23. L. O. Anderson, T. W. Barrowcliffe, E. Holmer, E. A. Johnson, and G. E. C. Sims, "Anticoagulant Properties of Heparin Fractionated by Affinity Chromatography on Matrix-Bound Antithrombin III and by Gel Filtration," Thromb. Res., 9, 575-583 (1976).

24. I. Björk and U. Lindahl, "Mechanism of the Anticoagulant Action of Heparin," Molecular and Cellular Biochemistry, 48, 161-182 (1982).

25. W. E. Hennink, C. D. Ebert, S. W. Kim, W. Breemhaar, A. Bantjes, and J. Feijen, "Interaction of Antithrombin III with Preadsorbed AlbuminHeparin Conjugates," Biomaterials, in press.

26. P. S. Damus, M. Hicks, and R. D. Rosenberg, "Anticoagulant Action of Heparin," Nature, 246, 355-357 (1973).

27. K. Kurachi, K. Fuijikawa, G. Schmer, and E. W. Davie, "Inhibition of Bovine Factor $\mathrm{Xa}$ and Factor $\mathrm{X} \alpha \beta$ by Antithrombin III," Biochemistry, 15, 373-377 (1976).

28. B. Osterud, M. Miller-Andersson, U. Abildgaard, and H. Prydz, "The Effect of Antithrombin III on the activity of the Coagulation Factors VII, IX and X," Thromb. Haem., 35, 295-303 (1976).

29. N. Stead, A. P. Kaplan, and R. D. Rosenberg, "Inhibition of Activated Factor XII by Antithrombin-Heparin Cofactor," J. Biol. Chem., 251, 64816488 (1976).

30. G. van Dedem, F. van Houdenhoven, and W. E. Hennink, "The USP Heparin Assay Fact and Artefact," in Chemistry and Biology of Heparin, (R. L. Lundblad, W. V. Brown, K. G. Mann, and H. R. Roberts, Eds., Elsevier-North Holland, Amsterdam, 1981, pp. 19-28.

Received December 5, 1983

Accepted March 26, 1984 